\title{
Compostagem como proposta didática para falar sobre solos no ensino fundamental
}

\author{
Composting as didactic proposal to talk about soil in elementary school
}

\author{
M. A. F. S. Lustosa ${ }^{1, *}$; L. A. $\operatorname{Santos}^{1}$; A. L. Freitas ${ }^{1}$; A. F. M. Vital ${ }^{2}$ \\ ${ }^{1}$ Unidade Acadêmica de Ciências Biológicas/Centro de Saúde e Tecnologia Rural, Universidade Federal de \\ Campina Grande, CEP 58708-110, Patos-PB, Brasil \\ ${ }^{2}$ Unidade Acadêmica de Tecnologia do Desenvolvimento/Centro de Desenvolvimento Sustentável do Semiárido, \\ Universidade Federal de Campina Grande, CEP 58540-000, Sumé-PB, Brasil
}

*cidafelix15@hotmail.com

(Recebido em 27 de setembro de 2017; aceito em 26 de dezembro de 2017)

\begin{abstract}
A vida moderna propicia uma crescente demanda de resíduos, chamados popularmente de lixo, cuja disposição inadequada constitui um dos principais problemas ambientais, sendo urgentes medidas que estimulem nas escolas a prática da reciclagem dos resíduos orgânicos. O trabalho foi realizado na Escola Municipal Ensino Fundamental Manuel Nunes Trindade, município de Mãe D’Água, Paraíba, com alunos de faixa etária entre $10(\mathrm{dez})$ e 17 (dezessete) anos. O objetivo dessa pesquisa foi apresentar a prática da compostagem em turmas de $6^{\circ}$ e $7^{\circ}$ anos e verificar, a partir das respostas dos alunos, se esta atividade contribui para dialogar sobre as práticas conservacionistas, na perspectiva da Educação em Solos, buscando a formação cidadã. A pesquisa foi realizada em cinco etapas: aplicação do questionário com 5 (cinco) perguntas e 12 (doze) itens segundo modelo da escala de Likert abordando conteúdos sobre solo, lixo e compostagem. Para condução da pesquisa foram realizadas aulas expositivas e oficina de compostagem. Ao final foi reaplicado o questionário para comparação da aprendizagem. Dos estudantes entrevistados, 69,35\% afirmaram ter bom ou muito interesse em estudar sobre a importância da conservação do solo. Após a realização das atividades teórica e prática esse percentual alterou-se para 88,71\%. Inicialmente 43,55\%, dos alunos percebiam que o lixo provocava contaminação do solo e apresentaram pouco conhecimento sobre o que é a compostagem. Com a realização das práticas pedagógicas 59,68\% dos estudantes conseguiram conceituar corretamente esse processo. Foi possível perceber que a importância do solo e a problemática do lixo são pouco abordadas no ambiente escolar.

Palavras chaves: Adubo orgânico, Conservação, Educação Ambiental.
\end{abstract}

Modern life leads to a growing demand for waste, popularly known as waste, whose inadequate disposal is one of the main environmental problems, and urgent measures are needed to stimulate recycling of organic waste in schools. The work was carried out at the Manuel Nunes Trindade Municipal Primary School, in the municipality of Mãe D'Água, Paraíba, with students between 10 (ten) and 17 (seventeen) years of age. The objective of this research was to present the practice of composting in 6th and 7th grade classes and to verify, from the students' answers, if this activity contributes to a dialogue about conservation practices, from the perspective of Soil Education, aiming at citizen training. The research was carried out in five stages: application of the questionnaire with 5 (five) questions and 12 (twelve) items according to Likert scale model addressing soil, garbage and composting contents. To conduct the research were lectures and workshop composting. At the end, the questionnaire for comparison of learning was reapplied. Of the students interviewed, $69.35 \%$ stated that they had good or very good interest in studying the importance of soil conservation. After performing the theoretical and practical activities, this percentage changed to $88.71 \%$. Initially $43.55 \%$ of the students perceived that the litter caused soil contamination and showed little knowledge about what composting is. With the accomplishment of the pedagogical practices $59,68 \%$ of the students managed to correctly conceptualize this process. It was possible to perceive that the importance of the soil and the problem of garbage are little discussed in the school environment Keywords: Organic fertilizer, Conservation, Environmental education.

\section{INTRODUÇÃO}

O solo é o grande reservatório da vida, todavia, diversas ações humanas promovem contaminação e poluição em suas interfaces, como os desmatamentos, as queimadas e o lixo. A 
geração de resíduos sólidos e a sua disposição de maneira inadequada no ambiente natural é uma problemática cada vez mais presente, trazendo como consequências muitos problemas ambientais, como a poluição dos solos e mananciais de água, a morte de diferentes organismos e doenças [1].

No Brasil em 2015, 30 milhões de toneladas de resíduos foram depositados inadequadamente em aterros controlados ou lixões sem nenhuma medida de tratamento adequada para evitar a contaminação e degradação da natureza [2]. O solo como componente dos diversos ecossistemas, sofre a ação antrópica e perde em qualidade, comprometendo seriamente a vida de todos os seres vivos. É urgente promover ações que busquem sensibilizar as pessoas para o cuidado com o solo e a escola é o espaço onde a formação cidadã tem continuidade.

O solo é um componente essencial para o equilíbrio nos ecossistemas naturais. É um fator importante para o desenvolvimento das plantas, armazenam nutrientes, controla o fluxo de água, fornece abrigo para diferentes seres vivos e controla o ciclo do carbono na atmosfera [3]. A degradação do solo é um problema de influência mundial e apresenta muita relevância, já que ocorre de maneira rápida ocasionando prejuízos elevados a economia e ao meio ambiente [4].

Mudanças de hábitos são urgentes, pois com o crescimento socioeconômico e o consumo exagerado de bens torna-se cada vez mais expressivo o avanço e a destruição de recursos naturais [5]. As pessoas precisam ser educadas com relação aos problemas ambientais que as afetam de maneira que sejam mostrados princípios fundamentais e conceitos de fácil entendimento relacionados com decisões particulares e sociais relacionados à interação do ambiente com a sociedade e a economia [6]. Dentre as atividades que podem ser implementadas nas escolas para promover a sensibilização para com o cuidado com o solo pode ser citada a compostagem, que é uma prática simples para a problemática da geração de resíduos sólidos, por meio da reciclagem [5].

A Política Nacional de Resíduos Sólidos reconhece que os resíduos sólidos reutilizados e reciclados são recursos de importância econômica e social, pois contribuem para geração de renda e promove a cidadania [7]. O processo de compostagem recicla a matéria orgânica de origem vegetal e animal e forma um composto orgânico que melhora a qualidade do solo sem agredir o meio ambiente e contribui para redução do acúmulo desses resíduos nos aterros [8]. O professor, ao abordar a temática dos processos que ocorrem no solo na sala de aula, estará despertando o interesse dos estudantes em estudar sobre a importância desse recurso natural [9].

Nesse aspecto a escola se torna uma mediadora para sensibilização da sociedade, visto que, no ambiente escolar ocorre uma troca de conhecimento trazido pelos estudantes e conhecimento científico. O tema lixo e compostagem assim como outros, devem ser discutidos na escola de uma maneira reflexiva envolvendo toda a comunidade.

Quando utilizada em aulas práticas de Ciências e Geografia a compostagem promove a união ensino/pesquisa e a interdisciplinaridade entres disciplinas curriculares, pois contextualiza o conteúdo passado pelo professor com o cotidiano do aluno, o que desperta seu interesse pelas aulas bem como seu caráter investigativo a respeito do tema estudado [10]. Os alunos precisam entender o seu papel enquanto cidadão para poder atuar como agentes transformadores do seu meio, contribuindo assim para a difusão de ações que visem o cuidado com o meio ambiente [11].

É com essa intenção educativa que a escola deve participar ativa e integralmente da formação dos estudantes como sujeitos capazes de compreender e agir de forma crítica e transformadora, trazendo para a discussão do cotidiano escolar as vivências e preocupações da localidade. Nesse contexto a presente pesquisa teve como objetivo apresentar a prática da compostagem em turmas de $6^{\circ}$ e $7^{\circ}$ anos e verificar, a partir das respostas dos alunos, se esta atividade contribui para dialogar sobre as práticas conservacionistas, na perspectiva da Educação em Solos, buscando a formação cidadã.

\section{MATERIAL E MÉTODOS}

\section{1. Área de Estudo, População e Amostra}

A pesquisa foi realizada durante os meses de maio a julho de 2017, na Escola Municipal de Ensino Fundamental Manuel Nunes Trindade, situada no centro do município de Mãe D' 
Água-PB, município localizado na Mesorregião do Sertão do Paraibano, bioma Caatinga, bacia hidrográfica do rio Piranhas e que apresenta uma área de $246 \mathrm{~km}^{2}$, estando referenciado sob as seguintes coordenadas geográficas: $07^{\circ} 15^{\prime} 27.81^{\prime \prime} \mathrm{S}$ e $037^{\circ} 25^{\prime} 36.66^{\prime \prime} \mathrm{O}$. A população é de aproximadamente 4 mil habitantes IBGE [12].

A seleção dos estudantes envolvidos na pesquisa foi feita a partir do número total de alunos matriculados, na escola $(\mathrm{N}=202)$, considerando um erro padrão igual a $10 \%$ [13]. Dessa forma, a amostragem constituiu de 63 alunos. Foram selecionados estudantes de maneira aleatória cursando o $6^{\circ}$ e $7^{\circ}$ ano do ensino fundamental distribuídas em três turmas.

\subsection{Coleta de Dados}

Para a realização das atividades, foram organizados os seguintes procedimentos metodológicos:

- Etapa 1: Foi realizado um primeiro contato com a comunidade escolar para apresentar a proposta à direção e aos professores de Ciências, assim como explicar aos estudantes o que seria desenvolvido para contribuir com o seu aprendizado e dessa maneira, envolvêlos e motivá-los a participarem.

- Etapa 2: Foi aplicado inicialmente um questionário constituído por 3 (três) perguntas discursivas e 2 (dois) objetivas e 12 (doze) itens segundo o modelo da escala de Likert, com 5 (cinco) níveis de respostas que variam entre "discordo completamente (nível 1) a concordo completamente (nível 5)". A escala de Likert determina o grau de especificidade de concordância com uma afirmação [14].

- Etapa 3: Foi ministrada aulas teóricas para contextualizar a proposta, sensibilizando os estudantes para a temática da geração do lixo, degradação e conservação do solo.

- Etapa 4: Foi construída uma leira, com objetivo de fazer a compostagem, utilizando o lixo orgânico trazido pelos estudantes das suas casas para promover a sensibilização sobre o aproveitamento do lixo como alternativa de adubação orgânica (Figura 1). A leira foi revolvida e umedecida a cada três dias.

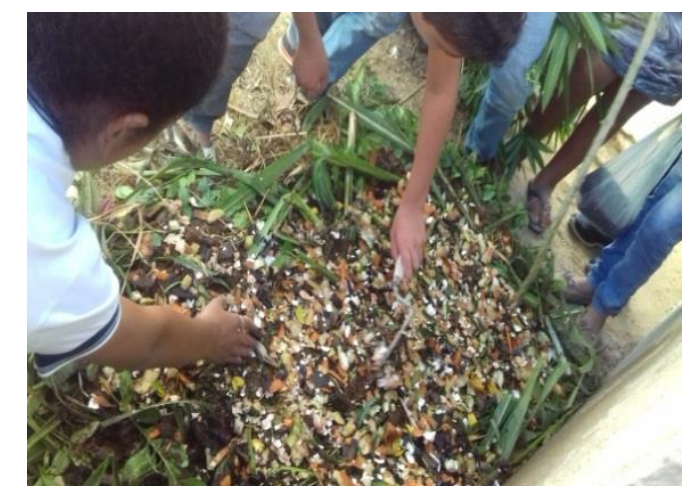

Figura 1: Realização de oficina sobre compostagem. Mãe DÁgua - PB, 2017. Fonte: Lustosa, 2017

- Etapa 5: Após uma semana da realização da prática de ensino e da construção da leira houve a reaplicação do questionário aplicado na etapa 2 , com a finalidade de avaliar o nível de conhecimento adquirido pelos estudantes. Parte do composto orgânico produzido foi distribuído entre os estudantes e a outra parte ficou na própria escola para futuramente ser usado na horta que será construída na comunidade escolar (Figura 2). 


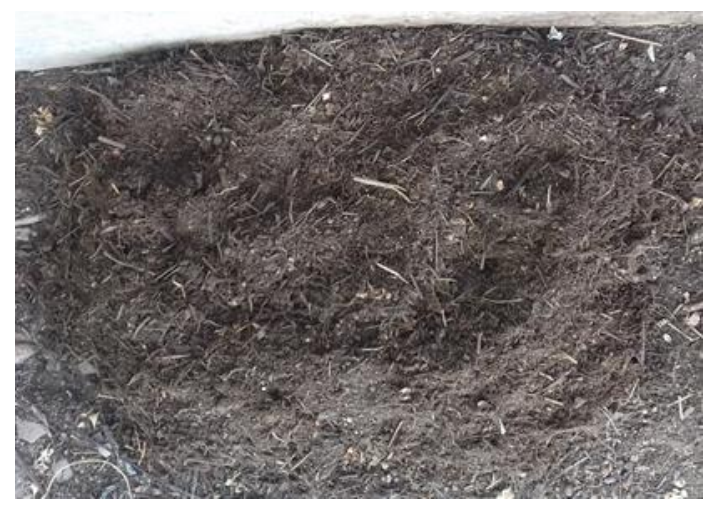

Figura 2: Composto orgânico produzido no final da pesquisa. Mãe D'Agua - PB, 2017. Fonte: Lustosa, 2017

A pesquisa foi desenvolvida mediante autorização do responsável da instituição mencionada anteriormente, e aprovação do Comitê de Ética da UFCG. Após esclarecimentos quanto ao objetivo da pesquisa à direção da escola e aos responsáveis pelos alunos, os mesmos, assinaram o Termo de Consentimento Livre e Esclarecido (TCLE).

\subsection{Análise dos dados}

Os dados do questionário foram analisados de maneira qualitativa e quantitativa por meio da estatística descritiva, utilizando Microsoft Excel 365. As respostas foram analisadas em percentuais e consideradas como: certa, certa em parte, errada ou não soube responder. Para avaliar a resposta da pergunta qualitativa, O que é Compostagem?, foi utilizado o conceito de acordo com [15] que diz:

Que a compostagem é um processo de decomposição da matéria orgânica na presença do oxigênio para produção de adubo orgânico que pode ser utilizado no cultivo de plantas e na recuperação de solos degradados (p. 25, 2017) [15].

\section{RESULTADOS E DISCUSSÃO}

Dentre os entrevistados, 47,6\%, $(n=30)$ foram do gênero feminino e $52,3 \%,(n=33)$ do gênero masculino, com faixa etária entre 10 e 17 anos; destes $71,5 \%$ residem na zona urbana e $28,5 \%$ na rural. Dos estudantes entrevistados, $69,35 \%,(n=43)$ afirmaram ter bom ou muito interesse em estudar sobre a importância da conservação do solo e 85,48\%, $(n=53)$ sobre a conservação dos rios, lagos e mares e dos animais. Após serem ministradas aulas teóricas e realizada uma oficina sobre compostagem, esse percentual modificou-se, para 88,71\%, $(n=55)$ para ambas as perguntas (Tabelas 1 e 2).

Tabela 1: Frequência percentual de interesse dos alunos em estudar conteúdos relacionados à conservação dos recursos naturais na Escola Manuel Nunes Trindade antes e após, a realização das atividades desta pesquisa. Mãe D’Agua - PB, 2017.

\begin{tabular}{lr|r|c|c|cc}
\hline \multirow{1}{*}{\multicolumn{1}{c}{ Item }} & \multicolumn{3}{c|}{ Antes } & \multicolumn{3}{c}{ Após } \\
\cline { 2 - 7 } \multicolumn{1}{c}{} & NPI & \multicolumn{1}{c}{ RI } & BMI & NPI & \multicolumn{1}{c}{ RI } & BMI \\
\hline Conservação do Solo & 11,29 & 19,35 & 69,35 & 0,00 & 11,29 & 88,71 \\
Conservação dos rios, lagos e mares & 3,23 & 11,29 & 85,48 & 1,61 & 9,68 & 88,71 \\
Conservação das plantas & 1,61 & 1,61 & 85,48 & 0,00 & 14,52 & 96,77 \\
Conservação dos animais & 4,84 & 9,68 & 85,48 & 0,00 & 14,52 & 85,48 \\
Conservação do ar & 1,61 & 16,13 & 82,26 & 1,61 & 6,45 & 91,94 \\
\hline
\end{tabular}

(NPI - Nenhum ou pouco interesse; RI - razoável interesse; BMI - bom ou muito interesse).

Fonte: Lustosa, 2017 
Antes da abordagem das temáticas relacionadas à conservação do solo e de outros recursos naturais, a cerca $85,48 \%,(n=53)$ dos estudantes, pois demonstraram bom ou muito interesse sobre a conservação das plantas e $82,26 \%, \mathrm{n}=51,0$ para conservação do ar. Após a reaplicação do questionário esses percentuais se modificaram para 96,77\%, $(n=60)$ e 91,94\%, (n =57), respectivamente.

Os resultados demonstraram que mesmo antes da realização das atividades os estudantes já apresentavam interesse em estudar conteúdos que relacionassem estratégias de conservação dos recursos naturais reforçando o que relatam Dias e Carneiro (2016) [16] quando afirmam que para que a formação cidadão com responsabilidade aconteça, os estudantes dentro do seu nível de aprendizado, precisam compreender os problemas e alternativas de sustentabilidade que cercam as questões ambientais.

Para a temática do solo como fator importante para nossa qualidade de vida 74,19\%, $(\mathrm{n}=$ 46) concordaram que o solo é muito importante para sua qualidade de vida e após os esclarecimentos da importância deste recurso esse percentual modificou-se para 93,55\%, $(n=58)$ (Tabela 2).

Segundo Silva et al. (2015) [17] o solo é um fator essencial para o meio ambiente servindo de suporte para o desenvolvimento para diferentes seres vivos, mas é pouco valorizado ao ser estudado no ensino fundamental. Corroborando essa assertiva, Aráujo e Costa (2015) [18] apontam que a educação ambiental voltada às temáticas dos solos no ensino fundamental e médio contribui para o conhecimento prático, pois os livros didáticos em teoria não demonstram a sua importância.

Os estudantes $53,23 \%,(n=33)$ afirmaram que os professores sempre ensinam sobre as características do solo. Após a reaplicação do questionário esse percentual diminui para 45,16\%, $(n=28)$. Nesse sentido, os resultados desse trabalho corroboram com Comin et al.(2013) [19] que relata que o solo é reconhecido pela ciência como um fator importante, mas sua abordagem não é realizada corretamente muitas vezes por falta de conhecimentos por parte do professor.

Com relação aos problemas causados pelo lixo 74,19\% ( $\mathrm{n}=46)$ dos estudantes demonstraram ter bom ou muito conhecimento que o lixo contamina água e 43,55\%, $(n=27)$ afirmaram ter bom ou muito conhecimento sobre a contaminação que o lixo provoca ao solo e $63,13 \%, \mathrm{n}=39$ afirmaram ter bom ou muito conhecimento da contaminação do ar. Depois de trabalhada a temática com abordagem em sala e com a realização da oficina os percentuais observados foram 90,32\%, $(n=56) ; 87,10 \%,(n=54)$ e 91,94\%, $(n=57)$, respectivamente (Tabela 2).

Antes da aplicação do questionário $66,13 \%,(\mathrm{n}=41)$ dos estudantes afirmaram ter bom ou muito conhecimento sobre a capacidade do lixo em atrair insetos e outros animais transmissores de doenças. Após reaplicação do questionário esse percentual elevou-se para $95,16 \%,(\mathrm{n}=59)$.

Inicialmente $80,65 \%,(n=50)$ dos estudantes percebiam que o lixo contamina o solo. Após os esclarecimentos esse percentual elevou-se consideravelmente para 93,55\%, $(n=58)$.

Para a pergunta você sabe quais os problemas que o lixo pode causar? Foram observadas as seguintes respostas:

Aluno: W: "Atrair insetos, causar doenças e a contaminação de muitos lugares."

Aluno: G: "Problemas na saúde, poluição do solo, poluição do ar e etc."

Aluno: H: "Pode contaminar a água, plantas e o meio ambiente."

Aluno: R.: "Doenças, morte, infestação, contaminação do ar e água."

Aluno: M.: "Causa mau cheiro, poluição nos rios, lagos e sujeira."

Aluno: A: "Contaminação, poluição e doenças para os animais." 
Tabela 2: Frequência percentual de conhecimento dos estudantes entrevistados, antes e após a realização das atividades desta pesquisa. Mãe D’Agua - PB, 2017.

\begin{tabular}{|c|c|c|c|c|c|c|}
\hline \multirow{2}{*}{ Item } & \multicolumn{3}{|c|}{ Antes } & \multicolumn{3}{|c|}{ Após } \\
\hline & NPC & RC & BMC & NPC & RC & BMC \\
\hline Contaminação da água & 19,35 & 6,45 & 74,19 & 3,23 & 6,45 & 90,32 \\
\hline Contaminação do solo & 43,55 & 12,90 & 43,55 & 6,45 & 6,45 & 87,10 \\
\hline Contaminação do ar & 17,74 & 16,13 & 66,13 & 0,00 & 8,06 & 91,94 \\
\hline $\begin{array}{l}\text { Atrai insetos e outros animais causadores de } \\
\text { doenças }\end{array}$ & 25,81 & 8,06 & 66,13 & 1,61 & 3,23 & 95,16 \\
\hline Compostagem & 88,71 & 3,23 & 8,06 & 62,90 & 14,52 & 22,58 \\
\hline \multicolumn{7}{|c|}{ Importância do solo relacionado: } \\
\hline A qualidade de vida & 20,97 & 4,84 & 74,19 & 1,61 & 4,84 & 93,55 \\
\hline \multicolumn{7}{|c|}{ Abordagem de conteúdo pelos professores referente: } \\
\hline As características do solo & 19,35 & 27,42 & 53,23 & 19,35 & 35,48 & 45,16 \\
\hline
\end{tabular}

Fonte: Lustosa, 2017. (NPC - Nenhum ou pouco conhecimento; RC - razoável conhecimento; BMC - bom ou muito conhecimento).

Os resultados encontrados reforçam o que afirmam Correia et al.(2016) [20] em um estudo realizado com estudantes de escolas públicas e privadas do município de Bom Jesus do Itabapoana (RJ) onde os estudantes consideravam o lixo como agente causador de doenças. Segundo Alves (2017) [21], os resíduos depositados inadequadamente além de atrair vetores que são responsáveis pela disseminação de doenças, ainda geram problemas estéticos e entre vizinhos.

Com relação ao destino dado ao lixo nas suas casas 93,54\%, $(\mathrm{n}=57)$ dos alunos afirmaram que colocam em sacolas para ser levado para o lixão e $6,46 \%,(n=5)$ queimam. Dados similares foram reportados por Silva et al.(2013) [22] que constataram em um estudo realizado em três escolas estaduais de rede pública do município de Muzambinho - MG, que 96,66\% dos entrevistados colocavam o lixo em frente às casas para o caminhão de limpeza levar e 3,34\% queimavam.

Cerca de 58,06\% $(\mathrm{n}=36)$ dos alunos, responderam que nunca visitaram o lixão da cidade e 41,94\%, $(n=26)$ afirmaram que já haviam frequentado o local. Nesse sentido, percebe-se que não existe uma medida sócia educativa voltada para diminuição de resíduos destinados aos lixões das cidades sendo necessária a introdução de atividades voltadas para educação ambiental, visando à sensibilização dos estudantes para atuarem como disseminadores dessa ideia.

Foi observado que não existe o hábito de separação e o reaproveitamento do lixo orgânico em suas casas. Esse fato é reforçado pela falta de ações que envolvam a separação do lixo, já que atualmente a cidade não possui um sistema de coleta seletiva. A temática da problemática do lixo na escola é pouco abordada, visto que os alunos ainda têm uma concepção errada do que seja realmente lixo. Dados similares foram observados por Correia et al.(2016) [20] onde 83\% dos alunos de escolas privadas e $77 \%$ das públicas relataram não realizar a separação do lixo em suas casas. Ao responderem o questionário inicial, $62 \%$ e $72 \%$, respectivamente não souberam conceituar o que era lixo. O local da realização da pesquisa também não possuía um sistema de coleta seletiva. Esse problema gera o descaso com o solo e sua qualidade, comprometendo seriamente a conservação ambiental. Dessa forma a abordagem de temas relacionados à educação ambiental se faz necessária no ambiente escolar.

Para a temática sobre compostagem foi observado que os alunos não possuíam familiaridade com tal prática tendo em vista que $69,35 \%,(n=43)$ dos estudantes não souberam conceituar este processo antes da realização das atividades. As práticas didáticas proporcionaram um melhor entendimento a respeito do processo de compostagem, já que após a reaplicação do questionário 59,68\%, $(\mathrm{n}=37)$ dos alunos conceituaram de maneira certa o processo de compostagem. Também foi possível perceber uma diminuição no percentual dos estudantes que 
não souberam responder o que era compostagem no questionário inicial demonstrando assim aquisição de conhecimento após a realização das atividades (Tabela 3).

Tais resultados corroboram com o trabalho de Lima et al. (2016) [3] que também observaram em pesquisa realizada em uma escola da rede pública municipal de São Miguel do Guamá (PA), que após as aulas ministradas e a construção de uma composteira, o conhecimento dos alunos melhorou, pois ao responderem novamente ao questionário inicial $100 \%$ dos alunos passaram, a saber, conceituar o processo de compostagem (Tabela 3).

Tabela 3: Frequência percentual das respostas dos alunos entrevistados para o conceito de compostagem. Mãe D’Agua - PB, 2017.

\begin{tabular}{ccccc}
\hline $\begin{array}{c}\text { Etapa da } \\
\text { pesquisa }\end{array}$ & Certo & Certo em partes & Errado & $\begin{array}{c}\text { Não soube } \\
\text { responder }\end{array}$ \\
\hline & & Compostagem & \\
\hline Antes & 11,29 & 8,06 & 11,29 & 69,35 \\
Após & 59,68 & 22,58 & 6,45 & 11,29 \\
\hline
\end{tabular}

Fonte: Lustosa, 2017

Após a reaplicação do questionário alguns alunos melhoraram o conceito para definir o processo de compostagem. Percebe-se que as metodologias realizadas acrescentaram aprendizagem em sala de aula:

Aluno: X.: "Compostagem é a decomposição de alimentos que se transforma em nutrientes para o solo".

Aluno: Y: "A decomposição por organismo do solo de restos de plantas para fazer adubo orgânico."

Aluno: Z: "É utilizada restos de alimentos para fazer adubo e é muito legal."

A maioria dos estudantes $43,54 \%,(n=27)$, conceituaram o processo de compostagem como sendo "a decomposição dos restos de alimentos para fazer adubo." Segundo Brasil (2017) [15] a compostagem pode auxiliar como ferramenta para educação ambiental, pois mobiliza e integra toda a comunidade escolar. Sendo assim a abordagem de temas interdisciplinares por meio de práticas inovadoras no meio escolar é de suma importância para a efetivação da aprendizagem e formação de um cidadão consciente das práticas ambientais voltadas para conservação e preservação dos recursos naturais.

Os alunos mostraram muito entusiasmo durante a realização das atividades e participaram ativamente do processo de manutenção da leira de compostagem revolvendo e umedecendo-a (Figura 3). Durante a etapa de condução do processo de compostagem os estudantes relataram com entusiasmo que iriam ensinar em casa e usar o composto produzido nos vasos de plantas das mães, na horta de casa e nos canteiros dos quintais, contribuindo assim para a disseminação da ideia de compostagem como alternativa de cuidado e conservação do solo no seu meio social. Nessa perspectiva, Lustosa et al. (2017) [23] afirmam que a promoção do diálogo dos conteúdos considerados sem importância pelos estudantes com o conhecimento já trazido por eles, é uma forma de dinamizar as aulas, tornando-a mais desafiadoras.

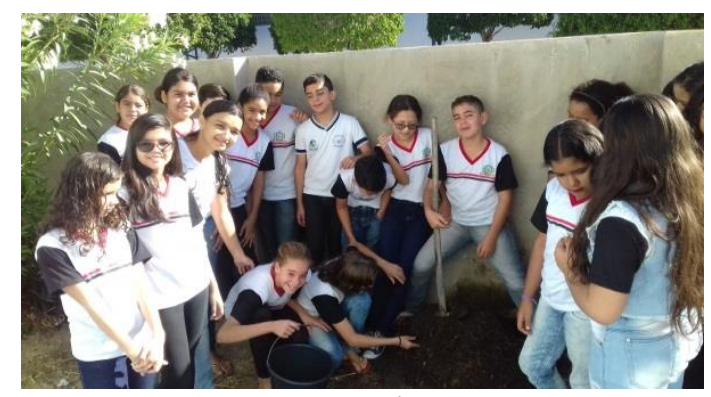

Figura 3: Revolvimento da leira. Mãe DÁgua - PB, 2017. Fonte: Lustosa, 2017 
Para que as ações que visem à conservação do solo e de outros recursos naturais surtam efeitos, os estudantes precisam estar envolvidos e familiarizados com tal assunto, para que sejam agentes transformadores no seu meio social. Além disso, dinamizar as aulas com as vivências dos educandos ou trazer metodologias inovadoras, dialógicas e participativas, contribui para que o processo ensino-aprendizagem se faça de maneira mais enriquecedora, promovendo reflexões e estimulando a mudança de atitudes e a adoção de posturas pró-ativas. Corroborando com essa ideia, Silva et al. (2016) [24] enfatizam que temas relacionados à realidade dos alunos devem ser considerados no ensino de ciências como ferramenta articuladora da interdisciplinaridade de conteúdos voltados para melhoria da qualidade de vida e do meio ambiente, sensibilizando-os sobre os problemas ambientais. Segundo Vital e Santos (2017) [25] o solo é o componente fundamental dos ecossistemas, presente na realidade das pessoas, e presente nas metodologias que estimulem o entendimento de seus conceitos, sendo uma oportunidade valiosa para minimizar processos de degradação, incentivando e oportunizando a formação cidadã, centrada na formação da consciência pedológica para uma vida melhor.

\section{CONCLUSÃO}

Os resultados permitiram observar que os estudantes apresentavam conhecimento incipiente ou não satisfatório de conceitos sobre o solo, bem como sobre o lixo orgânico. Além disso, o processo de compostagem era absolutamente desconhecido pelos estudantes. Essa constatação foi possível pela análise do questionário que antecedeu às atividades pedagógicas realizadas.

Verificou-se ainda que os estudantes apresentavam desconhecimento sobre a importância, funções e característica do solo aliado ao pouco entendimento da problemática da contaminação deste recurso ambiental pela disposição inadequada do lixo, tratado com descaso pelos representantes da comunidade, devendo ser trabalhado no ambiente escolar.

A partir da realização das atividades por meio das metodologias dialógicas e participativas adotadas os estudantes puderam interagir e demonstraram bastante entusiasmo pela oportunidade, que foi traduzido num melhor conhecimento relacionado à conservação do solo, reutilização e reciclagem do lixo produzido por meio da prática da compostagem.

Infere-se, portanto que as aulas que associam teoria e prática são mais efetivas para promoção de aprendizagem, permitindo reflexões e participação dos estudantes, que conseguem fixar melhor os conteúdos e ampliar o horizonte de percepções e aprendizados.

\section{AGRADECIMENTOS}

À direção, aos alunos e a todos os funcionários da Escola Municipal de Ensino Fundamental Manuel Nunes Trindade, Mãe D’Água-PB.

\section{REFERÊNCIAS BIBLIOGRÁFICAS}

1. Souza GS, Machado PB, Reis VR.; Santos AS, Dias VB. Educação ambiental como ferramenta para o manejo de resíduos sólidos no cotidiano escolar. Revista Brasileira de Educação Ambiental, 2013 8(2).

2. ABRELPE-Associação Brasileira de Empresas de Limpeza Pública e Resíduos Especiais, 2015.92 p. Disponível em: <http://www.abrelpe.org.br /Panorama/panorama2015.pdf>. Acessado em 22 de julho de 2017.

3. Lima GAC, Araújo PM, Reinaldo LRLR, Xavier RA. Textura do solo: importância da realização de atividades práticas no ensino de geografia. Revista Tamoios. 2015 11(2):177-188.

4. Eduardo EM, Carvalho DF, Machado RL, Soares PFC, Almeida WS. Erodibilidade, fatores cobertura e manejo e práticas conservacionistas em argissolo vermelho-amarelo, sob condições de chuva natural. Revista Brasileira de Ciências do Solo. 2013 37(3):796-803.

5. Lima GAA, Dias CAC, Lima AH. Compostagem de resíduos sólidos orgânicos como tema incentivador de educação ambiental. Scientia Plena. 2016 2(6). 
6. Araújo MFF, Pedrosa MA. Desenvolvimento sustentável e concepções de professores de biologia em formação inicial. Revista Ensaio. 2014 16(2):71-83.

7. Brasil. Política Nacional de Resíduos Sólidos. Brasília, 2 ed. Brasília DF: 69 p.; 2012. Disponível em:<http://fld.com.br/catadores/pdf/politica_residuos_solidos.pdf. Acessado em 02 de agosto de 2017.

8. Brasil. Ministério do Meio Ambiente. Secretaria de Recursos Hídricos e Ambiente Urbano. Manual para Implantação de Compostagem e de Coleta Seletiva no Âmbitode Consórcios Públicos. Brasília, DF: 69 p.;2010

9. Boas RCV, Moreira, FMS. Microbiologia do solo no ensino médio de Lavras, MG. Revista Brasileira de Ciência do Solo, 2012 36(1):295-306.

10. Costa AP, Silva WCM. A compostagem como recurso metodológico para o ensino de ciências naturais e geografia no ensino fundamental. Enciclopédia Biosfera. 2011 7(1):2-12.

11- Colombo SR. A Educação Ambiental como instrumento na formação da cidadania. Revista Brasileira de Pesquisa em Educação em Ciências. 2014 14(2):67-75.

12. IBGE - Instituto Brasileiro de Geografia Estatística. Disponível em:< http://www.cidades.ibge.gov.br/xtras/home.php?codnum=250>. Acessado em 28 de Abril de 2017.

13. Rocha JSM. Manual de Projetos Ambientais. Santa Maria: UFSM, 1997; 446.

14. Likert R. Technique for the measurement of atitudes. Archives of psychology. 1932 22(140):1-55. Disponível em:< http://www.voteview.com/pdf/Likert_1932.pdf. Acesso em: 19 de Maio de 2017.

15. Brasil. Ministério do Meio Ambiente. Compostagem doméstica, comunitária e institucional de resíduos orgânicos: manual de orientação / Ministério do Meio Ambiente, Centro de Estudos e Promoção da Agricultura de Grupo, Serviço Social do Comércio. Brasília, DF: 68 p.; 2017. Disponível em: http:// www.mma.gov.br/images/arquivo/80058/ompostagem-Manual Orientacao_MMA_2017-06-20.pdf. Acessado em 04 de agosto de 2017.

16. Dias DSS, Carneiro SMM. Projeto Cidadão Ambiental Mirim: contribuições à Educação Ambiental no ensino fundamental. Revista do Centro de Educação. 2016 41(2):399-410.

17. Silva TR, Silva JVF, Miyazaki LCP. A utilização de maquetes didáticas nos estudos de conservação e degradação dos solos no ensino fundamental. Periódico Eletrônico Fórum Ambiental da Alta Paulista. 2015 11(4):169-180.

18. Araújo FH; Silva Costa DF. Solo na educação ambiental: como proposta para o ensino fundamental e médio. Revista do CERES. 2015 1(2):255-258.

19. Comin FV, Furlan MC, Ferrony HM, Oliveira AL. O ensino de solos sob a perspectiva da educação ambiental: aplicação de experimentos para ensino e conscientização. RCA- Revista Científica da Ajes. $20134(9)$.

20. Correia JN; Figueiredo-de-Andrade CA; Lima NB. Lixo e reciclagem: a percepção ambiental de estudantes de escolas públicas e privadas do Município de Bom Jesus do Itabapoana (RJ). Humanas Sociais \& Aplicadas, [S.1.]. 2016 6(15):53-65.

21. Alves JB. A face oculta do lixo. Londrina: Mecenas; 2017. 144p.

22. Silva MCC, Pelá A, Barretos FRM. Impactos ambientais na destinação inadequada de resíduos sólidos urbanos na cidade de Ipameri-GO: um estudo de caso. Revista Eletronica em Gestão, Educação e Tecnologia Ambiental - REGET. 2013 17(17):3230-3239.

23. Lustosa MAFS, Santos Araújo RM, Silva GC, Marinho MGV, Silva, E. Saberes relacionados ao uso de plantas medicinais e influência na prática didática dos estudantes de Mãe D’Água, Paraíba, Brasil. Scientia Plena. 2017 13(6).

24. Silva LOE, Rodrigues ES, Mota ES. Técnicas de projetos: uma alternativa ao ensino aprendizagem a partir do tema gerador Educação Ambiental. Scientia Plena. 2016.

25. Vital AM, Santos RV. Solos, da educação à conservação: ações extensionistas. Maceió - AL: TexGraf; 2017. 94p. 